\title{
CONTRIBUIÇÕES DO DEBATE SOBRE AVALIAÇÃO DE POLÍTICAS PÚBLICAS PARA O CAMPO DA EDUCAÇÃO AMBIENTAL
}

\author{
Solange Reiguel Vieira ${ }^{1}$ \\ Marília Andrade Torales Campos²
}

Resumo: O artigo é tecido a partir de uma revisão da literatura sobre os estudos contemporâneos da política educacional no Brasil, buscando compreender os aspectos teórico-epistemológicos com ênfase na relação entre as políticas públicas e as práticas correlatas a elas no campo da Educação Ambiental. A estrutura orienta-se no sentido de contribuir com o debate sobre as seguintes questões: quais são os elementos teóricos e epistemológicos que sustentam a compreensão do Ciclo de Políticas? Como o processo de avaliação das políticas públicas se configura no campo das pesquisas? Quais são as possíveis contribuições do debate sobre a avaliação de políticas para o campo da Educação Ambiental? Quais são as reflexões e os desafios postos aos educadores ambientais? Os resultados demonstram que há uma ausência de estudos sobre a avaliação das políticas de Educação Ambiental no contexto escolar, principalmente que visem compreender como as escolas interpretam as políticas e assumem seu papel no processo de suas implementações. Esse resultado impõe reflexões aos que atuam no campo da Educação Ambiental, pois os processos avaliativos são fundamentais para o avanço das políticas públicas.

Palavras-chave: Questões Socioambientais; Políticas; Avaliação; Educadores Ambientais; Escola.

Abstract: The work is woven through a review the literature of contemporary studies of educational policy in Brazil, seeking understand the theoricalmethodological aspects with emphasis in the relationship between the policy and practice. From results are listed two questions main namely: what are possible contribute the debate the policy evaluation to the field of Environmental Education? What are reflections and challenges posed to environmental educators? There is an absence of studies on evaluation the environmental education in the school context, mainly to understand how schools interpret the policies and put into action.

Keywords: Environmental Questions; Policies; Evaluation; Environmental Educators; School.

1 Universidade Federal do Paraná. E-mail: solgeografia@gmail.com

2 Universidade Federal do Paraná. E-mail: mariliat.ufpr@gmail.com 


\section{Introdução}

A Educação Ambiental, compreendida como uma dimensão das políticas públicas, teve uma crescente evolução nos últimos vinte anos no Estado brasileiro. Seu marco legal estruturou-se, a partir da Constituição Federal (1988), ao incumbir o poder público, nos termos do Artigo 225, da promoção da Educação Ambiental em todos os níveis de ensino e a conscientização pública para a preservação do meio ambiente. A Lei Federal no 9.795/1999 segue a orientação legal que instituiu a Política Nacional de Educação Ambiental como um componente essencial e permanente da educação nacional, devendo estar presente, de forma articulada, em todos os níveis e modalidades do processo educativo, em caráter formal e não formal.

A política pública pode ser conceituada como um campo do conhecimento que busca colocar o governo em ação, conforme a demanda social. Após formuladas, as políticas "desdobram-se em planos, programas, projetos, bases de dados ou sistema de informação e pesquisas. Quando postas em ação, são implementadas, ficando daí submetidas a sistemas de acompanhamento e avaliação" (SOUZA, 2006, p. 26).

Nesse sentido, compreendemos que as questões socioambientais implicam em uma demanda social da arena política, na qual o "Estado precisa responder, ainda que com mínima intervenção direta, às demandas que surgem do conjunto articulado de instituições atuantes na Educação Ambiental crítica e emancipatória" (SORRENTINO et al., 2005, p. 285).

Nos dias atuais, colocam-se desafios para a implementação de políticas que se modificam constantemente; pois são condicionadas pelos novos cenários econômicos, culturais e socioambientais, decorrentes de diferentes modelos de desenvolvimento. Estes nos levam a refletir sobre o papel da Educação Ambiental diante das problemáticas contemporâneas, bem como a fazer novas propostas (BRASIL, 2018).

Vale sublinhar que no contexto escolar, no qual as políticas públicas se materializam, esses desafios têm sido cotidianamente (re)construídos, mas nem sempre resolvidos nem enfrentados com a expectativa que pretendem os educadores. Em vista disso, a Educação Ambiental precisaria, desde uma visão crítica, ser trabalhada como política pública estruturante, de forma efetiva, para a superação de projetos e programas pontuais (BIASOLI; SORRENTINO, 2018).

Percebe-se a importância do estudo das políticas educacionais que permitem conhecer e compreender o universo da gestão de governos na formulação, na implementação e na avaliação das políticas públicas. Por esses estudos, ampliam-se as possibilidades de avaliar as ações, os produtos e seus impactos, que requerem uma análise da relação entre a ação pública e as demandas sociais. É preciso, acima de tudo, considerar a efetivação da educação de qualidade como um direito, fundada nos princípios da justiça social e de democracia (SOUZA, 2016a; MAINARDES, 2006, 2018a). 
É nesse contexto que o trabalho é cunhado, por meio de uma revisão de literatura dos estudos contemporâneos da política educacional no Brasil, buscando compreender os aspectos teórico-epistemológicos e suas contribuições para a avaliação de políticas educacionais no campo da Educação Ambiental.

\section{Resultados e discussão}

A emergência e a constituição da política educacional, como campo acadêmico presente em diferentes países e contextos, são ainda iniciais; porém, apresenta amplas possibilidades de desenvolvimento de novas pesquisas (STREMEL;MAINARDES, 2016). Por conseguinte, apoiadas em Mainardes (2017, 2018a), poderíamos afirmar que a política educacional é um campo recente, abrangente, complexo, em construção e permanente expansão.

As pesquisas sobre políticas educacionais no Brasil iniciaram na década de 1960, mas, sobretudo a partir de 2010, houve um considerável desenvolvimento, do ponto de vista teórico e metodológico, como campo acadêmico para a pesquisa em política educacional. Por isso, tal campo necessita de um contínuo fortalecimento, principalmente na ampliação e diversificação dos estudos sobre as políticas educacionais para melhor compreensão da realidade e construção de alternativas sociais (MAINARDES, 2017, 2018b; MAINARDES; STREMEL; SOARES, 2018).

Em vista disso, faz-se necessária a contribuição dos educadores ambientais e pesquisadores do campo da Educação Ambiental nessa discussão teórica, assim como o envolvimento no processo de elaboração, implantação e avaliação das políticas públicas vinculadas à Política Nacional de Educação Ambiental e demais políticas correlatas ao campo.

M. Figueiredo e A. C. Figueiredo (1986) esclarecem que essa avaliação consiste em atribuir valor às políticas, também apresentam a necessidade de estabelecer critérios de avaliação para a escolha de uma política específica, no entanto, advertem que certamente se trata de um processo complexo e controverso. As escolhas antecedem a avaliação de políticas, tanto no estabelecimento de conexões lógicas entre objetivos e critérios de avaliação, como na definição de modelos de análise das políticas ou dos programas vinculados a elas.

No âmbito da política educacional, que se constitui em um campo de conhecimento específico formado por conhecimentos especializados, utilizamse modelos analíticos e abordagens metodológicas próprias, articuladas às perspectivas epistemológicas distintas, tais como: neomarxismo, estruturalismo, pós-estruturalismo, pluralismo. Assim, verifica-se a necessidade da explicitação da perspectiva epistemológica, a qual fundamenta as análises do pesquisador e contribui para a realização de pesquisas mais coerentes (MAINARDES, 2018a).

Mainardes (2018a) e Souza (2016a) têm se dedicado a apreciar o 
diferentes ângulos. Segundo eles, o objeto de estudo da política educacional constitui-se na análise de políticas que contemplam diferentes dimensões desse objeto, como: a análise do processo de sua formulação; seu conteúdo ou programa (discurso da política); os processos de sua implementação, tradução e interpretação ou programa no contexto da prática; e a sua avaliação (MAINARDES, 2018a).

Dentre as opções metodológicas apresentadas por Mainardes (2018a, p. 187) encontram-se abordagens que, a partir de uma análise crítica e aprofundada, poderiam ser empregadas na Educação Ambiental:

a) Estudos de natureza teórica sobre temas relacionados à política educacional (Estado, neoliberalismo, as relações entre o setor público e o privado, fundamentos teórico-metodológicos da pesquisa sobre políticas educacionais, epistemologias da política educacional, entre outros);

b) Análise de políticas (implementação, avaliação etc.);

c) Políticas educacionais e gestão (educacional e escolar);

d) Legislação educacional;

e) Financiamento da educação;

f) Políticas curriculares;

g) Políticas voltadas ao trabalho docente (formação, valorização, carreira etc.);

h) Questões relacionadas às demandas educacionais, oferta, acesso, qualidade, direito à educação, movimentos de luta pela garantia do direito à educação.

Em geral, as pesquisas de análise de políticas educacionais no Brasil utilizam a abordagem do "Ciclo de Políticas". Este se configura em uma ferramenta teórico-metodológica de orientação pós-moderna, baseada nos trabalhos de pesquisadores como Stephen Ball e Richard Bowe. Esta proposta estrutura-se com base na constituição de um ciclo contínuo com três contextos inter-relacionados, sem uma dimensão temporal, sequencial e/ou linear: o da influência, o da produção de texto e o da prática (MAINARDES, 2006).

O Ciclo de Política é composto pelas seguintes etapas: agenda (agenda setting); produção (policy formulation); decisão (decision makers); implementação (implementation); avaliação (policy evaluation); conclusão do programa (program termination) (MULLER; SUREL, 2002).

Pode-se definir a agenda como um conjunto de problemas e pautas que necessita de atenção do governo para compor o debate e a construção das políticas públicas. No contexto nacional, a Educação Ambiental faz parte da demanda política nacional, principalmente para o enfrentamento da problemática ambiental contemporânea, para a promoção de mudanças socioambientais e culturais, para a construção de sociedades sustentáveis e de uma cidadania mais crítica e consciente. Nas últimas décadas, a Educação Ambiental passou por um processo de institucionalização como política pública 
e está contemplada em algumas políticas ambientais e educacionais implementadas pelas instituições públicas (Governo, secretarias, escolas etc.) - que, porquanto parte fundamentais nas políticas, necessitam de acompanhamento e avaliação constantes.

Nessa abordagem, como assevera Mainardes (2006, p. 50-51): "o foco da análise das políticas públicas deveria incidir sobre a formação do discurso da política e sobre a interpretação ativa que os profissionais que atuam no contexto da prática fazem para relacionar os textos da política à prática". Dessa maneira, os sujeitos do contexto da prática têm um papel ativo no processo de interpretação, reinterpretação e implantação das políticas educacionais.

No contexto da Educação Ambiental, na etapa da avaliação seria preciso analisar em que medida as ações educativo-ambientais contribuíram para solucionar a problemática social e ambiental que gerou a demanda e as necessidades de prevenção, mitigação, adaptação para a melhoria da qualidade do ambiente e, por consequência, da própria sociedade. Diante disso, ao avaliar uma política socioambiental, é importante saber a noção de eficácia, efetividade e impacto descritas a seguir:

A avaliação de processos afere a eficácia da execução do programa conforme as diretrizes e metas propostas, dentro dos limites toleráveis; a eficiência é definida pela relação entre os aspectos econômicos (custos), sociais ou políticos e os seus resultados, efeitos e benefícios; a efetividade decorre do resultado correspondente à demanda social que gerou a política, ou seja, perceptível pela mudança qualitativa entre o antes e o depois da sua execução, garantindo o controle das variáveis ambientais no período de implementação e avaliação. A partir da efetividade é possível medir o impacto de uma política, ou seja, do desempenho da ação pública, se os objetivos ou propósitos da política foram atingidos ou não, de ampla complexidade por relacionar a política proposta e as alterações dos atores sociais (FIGUEIREDO, M.; FIGUEIREDO, A. C., 1986).

Nesse processo de avaliação, principalmente no Brasil, o qual se configura num país de dimensões continentais e de grande diversidade cultural, é preciso ter em conta os estudos sobre o contexto de influência (sujeitos sociais e propósitos), o contexto da produção de texto (formulação do documento da política) e o contexto da prática (atuação/implementação). Esses contextos figuram como importantes aspectos para compreender e definir as políticas públicas em cenários mais amplos. Assim, com base em Ball, Maguire e Braun (2016), Mainardes (2018a, p. 194, grifo do autor) define essas dimensões como:

a) contextos situados: o cenário local, história da escola, fluxo 
b) culturas profissionais: valores, compromissos e experiências dos professores e políticas de gestão da escola;

c) contextos materiais: equipe de trabalho da escola, orçamento, prédios, tecnologia e infraestrutura;

d) contextos externos: nível e qualidade de apoio das autoridades locais de educação, pressões e expectativas do contexto político mais amplo, índices e taxas a serem atingidas, rankings, exigências e responsabilidades legais etc.

As pesquisas avaliativas em contextos necessitam reunir informações acerca da efetividade das políticas ou dos programas, suas potencialidades, limitações e alternativas; desse modo, pensar na complexidade das políticas requer uma reflexão sobre os resultados e efeitos a longo prazo. Isso pressupõe que os pesquisadores definam "uma concepção de educação e de um projeto de sociedade, que podem servir de parâmetros para avaliar os resultados/efeitos e as consequências das políticas, em uma perspectiva crítica" (MAINARDES, 2018a, p. 194).

Dentre os estudos teóricos sobre metodologias de análise de políticas públicas, Rus Perez (2010) traz importantes contribuições em seu trabalho intitulado "Por que pesquisar implementação de políticas educacionais atualmente?". Nesse artigo, o autor apresenta o processo de implementação de políticas educacionais como um campo fértil de pesquisa prática. A partir dos resultados empíricos da pesquisa, Rus Perez (2010) aponta três dimensões dos modelos de análise do processo de implementação de políticas educacionais: 1) as relações entre o desenho ou a formulação da política e os formatos que os programas adquirem ao final do processo; 2) a dimensão temporal do processo e seus efeitos diferenciados no tempo sobre a organização em que se processam, sobre os atores que empreendem resistências e adesões, e as modificações das condições iniciais; e 3) as condições que propiciam ou entravam o processo de implementação.

Essas três dimensões do modelo de análise de implementação requerem compreender as relações complexas entre as seguintes variáveis:

[...] variáveis dependentes (graus e formas da implementação), variáveis intervenientes (comportamento dos agentes envolvidos na implementação) e variáveis independentes (estrutura de operação da rede, envolvendo as dimensões organizacionais, jurídicas, financeiras e de apoio logístico). Além disso, considerase ainda, nesse nível, a dinâmica de ação dos atores (grau de conhecimento do processo, sistema de incentivo e de punição, opiniões, interesses etc.) (RUS PEREZ, 2010, p. 1098).

Dentre as pesquisas sobre políticas e programas que abrangem estudos mais focalizados em diferentes aspectos, destacam-se: o processo de formulação de políticas e programas, de implementação, de avaliação de 
políticas educacionais, da análise de resultados e consequências. Em suma, a política seria o horizonte, algo de longo alcance; enquanto os programas, as formas de colocar uma política em ação, constituindo-se em desdobramentos das políticas (MAINARDES, 2018a). Segundo esse autor, os estudos nesse foco trazem alguns desafios:

Ao analisar políticas e programas, os pesquisadores podem enfocar um aspecto da política ou programa ou ainda buscar uma análise mais integrada que abrange a análise da formulação, implementação e avaliação. Embora a análise aprofundada de uma única política ou programa seja relevante para a produção do conhecimento, compreender as relações existentes entre as políticas e programas constitui-se em um desafio para os pesquisadores (MAINARDES, 2018a, p. 193).

Outra importante contribuição teórico-metodológica para os estudos deste campo no Brasil está presente no livro Como as escolas fazem as políticas: atuação em escolas secundárias, de Ball, Maguire e Braun (2016). Os autores utilizam o conceito de atuação da política (policy enactment), que consiste no processo de interpretação, reinterpretação, tradução, criação e recriação das políticas realizadas por diversos atores sociais que colocam a política em ação no cotidiano da escola. Os autores ressaltam que:

No centro da atuação da política está a escola - mas a escola não é nenhuma entidade simples nem coerente. [...]. As escolas não são uma peça só. Elas são redes precárias de grupos diferentes e sobrepostos de pessoas, de artefatos e de práticas. [...]. As escolas são também diferentes lugares em diferentes épocas do ano, ou do dia, ou em partes do semestre - mais ou menos carregadas ou relaxadas. As escolas são organizações orgânicas que são, pelo menos em parte, o produto do seu contexto - perfis de pessoal, matrículas e aspirações dos pais bem como sendo influenciadas por aspectos práticos, tais como o alojamento da escola, a construção e o seu ambiente circundante. Há um contexto social e uma materialidade para a política. (BALL; MAGUIRE; BRAUN, 2016, p. 201).

Nesse sentido, os autores revelam que a escola é permeada por uma série de dimensões contextuais, que a torna um espaço privilegiado para a produção de políticas. Aproximando os estudos de Ball, Maguire e Braun (2016) aos de Rus Perez (2010), o acompanhamento do processo de implementação da política pública dos contextos da prática emerge de forma fundamental a fim de identificar os obstáculos e os elementos facilitadores deste processo, bem como evidencia a necessidade de compreender o grau de adesão e resistência dos agentes implementadores. 
No contexto da micropolítica, as escolas são consideradas instituições sólidas e basilares para a análise da política (policy), cujos atores são os implementadores que dão novos sentidos, significados e ressignificam a política. Por isso, Rus Perez (2010, p. 1089) afirma que, "como o processo de implementação dispõe de uma dinâmica no tempo, portanto mutável, é preciso também levar em consideração a comparação entre distintos tempos (inicial, intermediário e final)". Ele ainda frisa a necessidade de sopesar a inter-relação entre política, pessoas e lugares. Assim, de forma ambivalente, ambos concordam que a participação dos implementadores, em diversas comunidades e grupos de relacionamentos, é essencial para a implementação das políticas públicas.

Por outro lado, Biasoli e Sorrentino (2018, p. 7) contribuem com o debate ao promover um movimento dialético entre os campos dos estudos e das pesquisas sobre a avaliação de políticas e do campo da Educação Ambiental. As políticas públicas são identificadas como eixos estruturantes por serem planejadas e executadas de forma abrangente e por gerarem planos e programas permanentes, bem como atuarem na consolidação de instâncias administrativas e operacionais capazes de ajudar no monitoramento e avaliação. Os autores defendem um processo pedagógico, participativo e formativo com atores do cotidiano, visando à formulação e à implantação de políticas públicas, assim como a formação de sociedades sustentáveis. Com esse entendimento, apresentam a proposta da dimensão da política do cotidiano, que está relacionada à organização social e à participação na arena da política pública. Eles exibem alguns questionamentos que certamente contribuirão com a análise do processo da pesquisa:

Mas como despertar um olhar crítico dos distintos atores para estabelecerem prioridades e formar competências para identificar interesses implícitos e estarem preparados para a participação nas arenas políticas? Como garantir a ocorrência por todo o ciclo da política de espaços concretos de participação para que determinados temas sejam incluídos como pauta política? Como superar os obstáculos reiteradamente apontados, reconhecendo e compreendendo os meandros institucionais na implantação efetiva de políticas públicas? E, mais ainda, na implantação de uma política, como garantir que ela ocorra de forma participativa, com avaliações processuais que possibilitem o constante monitoramento e adaptações incrementais no percurso? (BIASOLI; SORRENTINO, 2018, p. 10).

Diante dos atuais quadros de pesquisa, pode-se considerar que as políticas educacionais e as avaliações da política têm respaldado a própria ação política e se tornado ferramenta imprescindível para governos elaborarem suas políticas (RUS PEREZ, 2010; SOUZA, 2014). Essas ações reverberam no contexto das escolas e podem dar potência às práticas pedagógicas 
relacionadas com a Educação Ambiental, recrudescendo-as e estimulando a insurgência de novas perspectivas de ação social ante as questões ambientais.

Nesta seara de construção de significados e alternativas, os estudos das políticas educacionais emergem com o intuito "de conhecer e mostrar como são operadas as relações entre o Estado e a Sociedade na luta pelo reconhecimento da educação como direito, nos desafios da sua oferta $e$ organização e nos conflitos decorrentes da busca por qualidade" (SOUZA, 2016a, p. 86). No bojo desse embate, a Educação Ambiental impõe-se como um elemento que permite repensar não só a totalidade do ciclo de políticas, mas também exige movimento de reestruturação para problematizar a própria relação entre o indivíduo e a sociedade e, desta, com a natureza.

\section{Conclusões}

Os resultados recrudescem os debates sobre a avaliação das políticas públicas no campo da Educação Ambiental, tendo em vista que permite compreender elementos que fundamentam as pesquisas contemporâneas sobre o Ciclo de Políticas. Nesse contexto pululam novos desafios que exigem reflexão e tomada de posição dos que atuam no campo da Educação Ambiental. Dentre essas reflexões, elencamos e comentamos duas.

1) Quais são as possíveis contribuições do debate da temática avaliação de políticas para o campo da Educação Ambiental?

Com base nos autores estudados (SORRENTINO et al., 2005; BIASOLI; SORRENTINO, 2018), é possível identificar fortes contribuições teóricoepistemológicas para a avaliação de políticas educacionais e para o entendimento da Educação Ambiental como política pública. Os estudos sistematizados neste artigo correlacionam o debate entre os campos da Educação Ambiental e a avaliação de políticas, o que aponta para a necessidade de avanços, em especial, para o monitoramento das políticas públicas nos âmbitos dos sistemas de ensino. Evidenciam, dessa forma, a importância da pesquisa em políticas educacionais e a expansão do campo no contexto científico e acadêmico, conforme visto nos estudos de Mainardes (2018a) e Souza (2016a). Estes autores nos ajudaram a conhecer processos e procedimentos de políticas educacionais, bem como permitiram aprofundar a análise da etapa de implementação de políticas ao apresentar estudos no campo de investigação das políticas educacionais e os objetos de estudo. Ball, Maguire e Braun (2016) desvelam o conceito de Ciclo de Políticas para análise e compreensão do processo de interpretação dessas pelos atores que as colocam em ação no cotidiano escolar. Por último, Rus Perez (2010) trouxe elementos para pensar sobre a importância dos estudos da implementação das políticas e destaca o papel dos agentes envolvidos, que podem influenciar nos resultados da política.

2) Quais são as reflexões e os desafios postos aos educadores ambientais?

Ao longo dos últimos anos de construção das políticas públicas no 
caminho entre a formulação das políticas e sua implementação. Mas, a partir disso, quais são os resultados dessas políticas no contexto brasileiro?

A produção $O$ que fazem as escolas que dizem que fazem Educação Ambiental?, da série Avaliação, organizada pelo Ministério da Educação em parceria com a UNESCO em 2004 (BRASIL, 2007), foi uma primeira iniciativa institucional para avaliar a Educação Ambiental nas escolas brasileiras, porém, não se tem notícias de estudos que continuaram a proposta. Há poucos registros de processos avaliativos nos últimos anos nessa perspectiva, apenas no âmbito da Conferência Nacional Infantojuvenil pelo Meio Ambiente, uma ação estruturante da Educação Ambiental. A partir da realização das Conferências, foram apresentados relatórios a cada edição com base nos dados da pesquisa realizada com as escolas participantes.

Evidencia-se uma ausência de estudos sistemáticos sobre a avaliação das políticas de Educação Ambiental no contexto escolar, principalmente de forma a compreender como as escolas interpretam as políticas e as colocam em ação. Por isso, repisamos a necessidade de ampliar iniciativas que favoreçam os processos de avaliação da implementação das políticas públicas de Educação Ambiental, assim como o desenvolvimento de instrumentos que possibilitem seus estudos. Portanto, os esforços realizados até o momento permitiram a construção de conhecimentos e reflexões acerca das políticas públicas educacionais concernentes à Educação Ambiental, mas com a consciência de que ainda há muito a ser construído no compromisso em contribuir para a construção de sociedades ambientalmente mais sustentáveis.

\section{Referências}

BALL, S. J.; MAGUIRE, M.; BRAUN, A. Como as escolas fazem as políticas: atuação em escolas secundárias. Ponta Grossa: Editora UEPG, 2016.

BIASOLI, S.; SORRENTINO, M. Dimensões das Políticas Públicas de Educação Ambiental: a necessária inclusão da política do cotidiano. Ambiente \& Sociedade. [online]. São Paulo, v.21, p. 1-18, 2018.

BRASIL. Constituição da República Federativa do Brasil, de 05 de outubro de 1988. Presidência da República. DF, 1988. Disponível em: $<$ http://www.planalto.gov.br/ccivil 03/Constituicao/Constituicao.htm>. Acesso em: 08 mai. 2019.

BRASIL. Lei n.o 9.795, de 27/04/1999. Institui a Política Nacional de Educação Ambiental e dá outras providências. Brasília, DF, 27 abr. 1999. Disponível em: $<$ http://www.planalto.gov.br/ccivil 03/leis/L9795.htm>. Acesso em: 08 mai. 2019.

BRASIL. Educação na diversidade: 0 que fazem as escolas que dizem que fazem Educação Ambiental. TRAJBER, R.; MENDONÇA, P.R. (Orgs.). Brasília: Secretaria de Educação Continuada, Alfabetização e Diversidade, 2007.

BRASIL. Programa Nacional de Educação Ambiental. Ministério do meio Ambiente. Educação Ambiental por um Brasil sustentável: ProNEA, marcos legais e normativos [recurso eletrônico]. Ministério do Meio Ambiente - MMA /Ministério da Educação - MEC. Brasília-DF:MMA, 2018. 
DALE, R. "Globalização e educação: demonstrando a existência de uma "Cultura Educacional Mundial Comum" ou localizando uma "Agenda Globalmente Estruturada para a Educação"? Educação \& Sociedade, v. 25, n. 87, p. 423-460, 2004.

FIGUEIREDO, M.; FIGUEIREDO, A. C. Avaliação Política e Avaliação de Políticas: Um Quadro de Referência Teórica. Fundação João Pinheiro, p. 108-129. 1986;

MAINARDES, J. Abordagem do ciclo de políticas: uma contribuição para a análise de políticas educacionais. Educação \& Sociedade, Campinas, v. 27, n. 94, jan./abr. 2006.

MAINARDES, J. Reiterpretando os ciclos de de aprendizagem. São Paulo: Cortez, 2007.

MAINARDES, J. A pesquisa sobre política no Brasil: análise de aspectos teóricoepistemológicos. Educação em Revista, n.33, p.1-25, 2017.

MAINARDES, J. Reflexões sobre o objeto de estudo da política educacional. Laplage em Revista (Sorocaba), v. 4, n. 1, p.186-201, jan.-abr. 2018a.

MAINARDES, J. A pesquisa no campo da política educacional: perspectivas teórico-epistemológicas e o lugar do pluralismo. Revista Brasileira de Educação, v. 23 , p. $1-20,2018 \mathrm{~b}$.

MAINARDES, J.; STREMEL, S.; SOARES, S. T. Aspectos teórico-epistemológicos da pesquisa em política educacional no Brasil: mapeamento e reflexões. Movimento-Revista de Educação, Niterói, ano 5, n.8, p.43-74, jan./jun. 2018.

MULLER, P; SUREL, Y. A Análise das Políticas Públicas. Pelotas: Educat, 2002.

RUS PEREZ, J. R. Por que pesquisar implementação de políticas educacionais atualmente? Revista Educação e Sociedade, Campinas, v. 31, n. 113, p. 11791193, out./dez. 2010.

SORRENTINO, M.; TRAJBER, R.; MENDONÇA, P.; FERRARO-JÚNIOR, L. A. A Educação Ambiental como política pública. Educação e Pesquisa, São Paulo, v. 31, n. 2, p. 285-299, mai./ago. 2005.

SOUZA, C. Políticas Públicas: uma revisão da literatura. Sociologias, Porto Alegre, ano 8, no 16, p. 20-45, jul./dez. 2006.

SOUZA, Â. R. de. A pesquisa em políticas educacionais no Brasil: de que estamos tratando? Práxis Educativa, v. 9, n. 2, p. 355-367, jul./dez. 2014.

SOUZA, Â. R. de. A política educacional e seus objetos de estudo. Revista de Estudios Teóricos y Epistemológicos en Política Educativa. v.1, n.1, p.75-89, jan./jun.2016a.

SOUZA, Â. R. de. A teoria da agenda globalmente estruturada para a educação e sua apropriação pela pesquisa em políticas educacionais. RBPAE, v. 32, n. 2, p. 463-485 mai./ago. 2016b.

STREMEL, S.; MAINARDES, J. A emergência do campo acadêmico da política educacional em diferentes países. Tópicos Educacionais, Recife, n.1, p. 62-85, jan./jun. 2016.

Revbea, São Paulo, V. 16, № 2: 248-258, 2021. 